\title{
Global Welfare Implications of Carbon Border Taxes
}

\author{
Daniel Gros
}

CESIFO WORKING PAPER NO. 2790

CATEGORY 9: RESOURCE AND ENVIRONMENT ECONOMICS

SEPTEMBER 2009

Presented at CESifo Venice Summer Institute, July 2009

\footnotetext{
An electronic version of the paper may be downloaded

- from the SSRN website: Www.SSRN.com

- from the RePEc website: Www.RePEc.org

- from the CESifo website: www.CESifo-group.org/wp
} 


\title{
Global Welfare Implications of Carbon Border Taxes
}

\begin{abstract}
This paper presents a simple, basic model to compute the welfare consequences of the introduction of a tariff on the $\mathrm{CO}_{2}$ content of imported goods in a country that already imposes a domestic carbon tax. The main finding is that the introduction of a carbon import tariff increases global welfare (and not just the welfare of the importing country) if there is no (or insufficient) pricing of carbon abroad. A higher domestic price of carbon justifies a higher import tariff. Moreover, a higher relative intensity of carbon abroad increases the desirability of high import tariff imposed by the home country because a border tax shifts production to the importing country, which in this case leads to lower environmental costs.

If both instruments are used to maximise global welfare, the optimal domestic price for carbon should be higher than the external effects (assuming that there is no carbon pricing in the rest of the world) and the optimal tariff rate would be somewhat lower than the domestic carbon price.

If the importing country has a fixed ceiling on emissions instead of a constant carbon price (as provided under the EU's Emissions Trading System), an import tariff is always beneficial from a global point of view and its imposition lowers the price of domestic allowances, but less than proportionally.
\end{abstract}

JEL Code: A10.

Keywords: carbon tax, tariffs, global welfare.

\author{
Daniel Gros \\ Centre for European Policy Studies \\ 1 Place du Congres \\ Belgium - 1000 Brussels \\ danielg@ceps.eu
}

This is a revised version of a paper presented at a CES/ifo conference in Venice, July 2009. I wish to thank conference participants for valuable comments. 


\section{Contents}

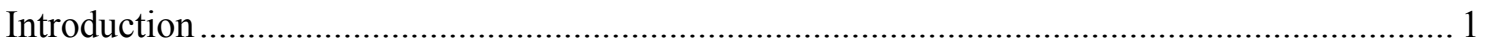

1. Simple illustration of the welfare gain from the introduction of a carbon tariff ...................... 2

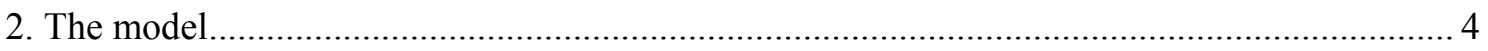

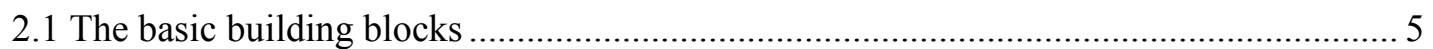

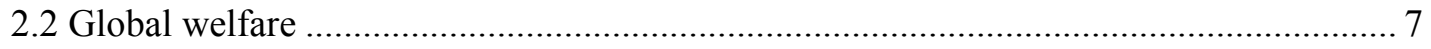

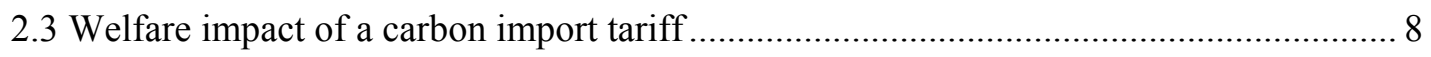

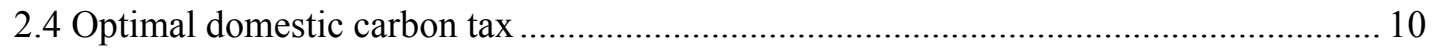

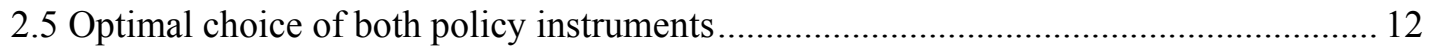

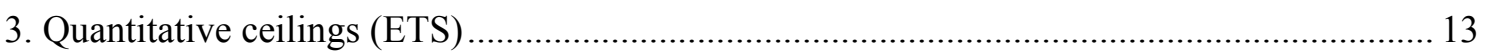

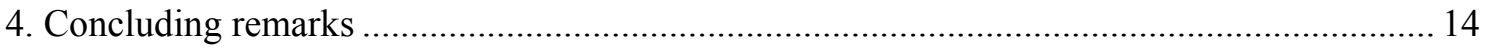

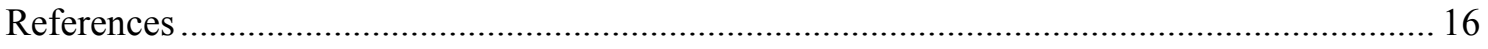

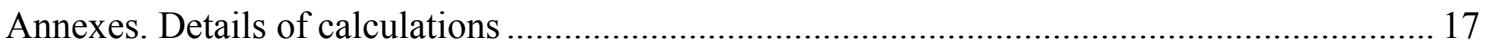




\title{
GLOBAL WELFARE IMPLICATIONS OF CARBON BORDER TAXES
}

\author{
DANIEL GROS*
}

\section{Introduction}

A key issue in the economics (and politics) of global climate change is whether those countries that have decided unilaterally to limit greenhouse gas emissions at home should also impose 'border measures' to protect their industries from competition from countries in which carbon is not priced. This issue has been extensively discussed in the rapidly growing body of literature on the economics of climate change mitigation policies, but most studies concentrate on competitiveness (of energy-intensive industries) and carbon leakage. Only a few studies examine the international trade impacts of a 'carbon border tax' and none seems to look at the welfare implications from a global point of view.

The purpose of this paper is thus to provide a solid basis for any discussion of the economics of 'border measures' to combat climate change. Since climate change policy, even when implemented at the national level is motivated by a concern for global (as opposed to national) welfare, it is important to adopt the same point of view when discussing so-called 'border measures'.

An important side issue in the discussion about 'border measures' is the distinction between plain import tariffs (on the carbon content of goods imported) and the combination of import tariffs plus export rebates. ${ }^{1}$

This paper focuses on the case where there is no export rebate. The model used here has only one good (of which the importing country is a net importer), and hence it cannot be used directly to assess the impact of the combination of an import tariff plus an export subsidy. However, this should not be of major importance given the well-known general result from the theoretical literature: a generalised (ad valorem) export subsidy coupled with an import tariff is equivalent to a depreciation of the nominal exchange rate and thus has no impact in the long run when all nominal variables can adjust.

By contrast, there is no consensus in the empirical literature whether a border tax (BTA) is effective or not, i.e. whether it can correct for the distortionary impacts of (national) climate mitigation policies that result in a loss of competitiveness and carbon leakage.

\footnotetext{
* Daniel Gros is Director at the Centre for European Policy Studies, Brussels. He gratefully acknowledges financial support from Confindustria. He also expresses his thanks to participants at a CES/ifo Workshop on the economics of global warming as well as to Selen Guerin and other colleagues for helpful discussions and comments.

${ }^{1}$ The combination of import tariffs and export refunds constitutes what is usually referred to as border tax adjustment or BTA. Of course the concept of border tax adjustment is not new, but its application to environmental problems is. According to the final report of the decisive GATT Working Party (1970), a BTA is defined "as any fiscal measure which put into effect, in whole or in part, the destination principle". The destination principle enables exported products to be reimbursed for some or all of the taxes changed in the exporting country and imported products to be charged with some or all of the taxes charged in the importing country (GATT Document L/3464). Furthermore, the Working Party concluded that only certain indirect taxes but not direct taxes (such as social security charges and payroll taxes) were eligible for tax adjustment. This conclusion was important for the EU as BTAs are widely used by the EU owing to the fact that member countries rely on indirect taxes (VAT).
} 
A recent study by Veenendaal \& Manders (2008) addresses directly the effectiveness of a carbon BTA on competitiveness and carbon leakage for the EU, assuming that the EU is the only country to follow this approach. In a general equilibrium analysis, they quantify the impact of a number of policy scenarios with a specific focus on the energy-intensive sectors covered by the EU's ETS (Emissions Trading System). They show that when there is no BTA (and no equivalent transfer mechanism in the form of a clean development mechanism or CDM), production and employment in these sectors are negatively affected by the imposition of a domestic tax on carbon (for example the ETS). However, the imposition of a BTA (but again no $\mathrm{CDM}$ ) can mitigate the loss of competitiveness: the loss in production and employment is halved. The overall welfare effects of the BTA for Europe is ambiguous since refunds are found to be welfare decreasing for Europe but import levies are welfare increasing. Overall the authors conclude that the impact of the BTA is too modest to make its implementation worthwhile. McKibben \& Wilcoxen (2008) reach a similar conclusion: the benefits from the BTA are too small to justify their administrative complexity. In contrast, Majocchi \& Missaglia (2001) use a general equilibrium model and show that BTAs are more likely to produce a better environment and less unemployment for the EU-15 member countries. Other empirical studies on sectoral impact give support to BTAs: Demailly \& Quirion (2005) show that the BTA can be effective in preventing carbon leakage in the cement industry whereas Mathiesen \& Maestad (2002) follow a similar exercise for the steel industry.

The remainder of the paper is organised as follows: Section 1 provides a brief illustration of the intuition behind the main results using a standard setting. Section 2 then sets out a simple, standard partial equilibrium model which allows one to calculate the welfare impact of border measures under a variety of circumstances. Within this model one can calculate whether a tariff should be introduced at all, the size of the optimal tariff and the size of the optimal combination of domestic carbon price and import tariff. In contrast to much of the existing literature, the focus in all of these calculations is always on global welfare.

The following short section 3 applies the same model in a different setting, namely one in which the importing country has a fixed ceiling on domestic emissions (and hence domestic production). It is shown there that the introduction of an import tariff always improves global welfare and that the level of the optimal tariff does not depend directly on the magnitude of the domestic emissions ceiling.

Section 4 concludes.

\section{Simple illustration of the welfare gain from the introduction of a carbon tariff}

This is a simple partial equilibrium illustration using linear demand and supply curves for simplicity to show graphically the impact of a carbon tax (i.e. a tariff on the carbon content of imports) on global welfare.

As usual the World is divided into two actors: an importing country (or group of importing countries) and the rest of the world (RoW).

Figure 1 shows the global demand and supply curves of the good in question. Production of the good leads to emission of $\mathrm{CO}_{2}$ (at a certain, given, per unit rate). Private producers do not take into account the cost of emissions: hence the private supply curve is below the supply curve, which takes into account the external impact of emissions. However, unless there is further government intervention, the international price of the good in question is determined by the intersection of private supply and demand, point $\mathrm{O}$ on the graph. 
For simplicity, we consider here the simplest case, which is when the home country introduces a 'cap and trade' system such as the ETS in Europe. In this case the global supply curve is kinked at the quantity at which the ETS limits the amount that can be produced in the home country (given the limit on emissions and the per unit emissions factor). After the introduction of the ETS, the world price of the good in question is determined then at point A by the intersection between the ('kinked', private) supply curve subject and the global demand curve. It is apparent that the price is higher than before.

Figure 1. Equilibrium without tariffs

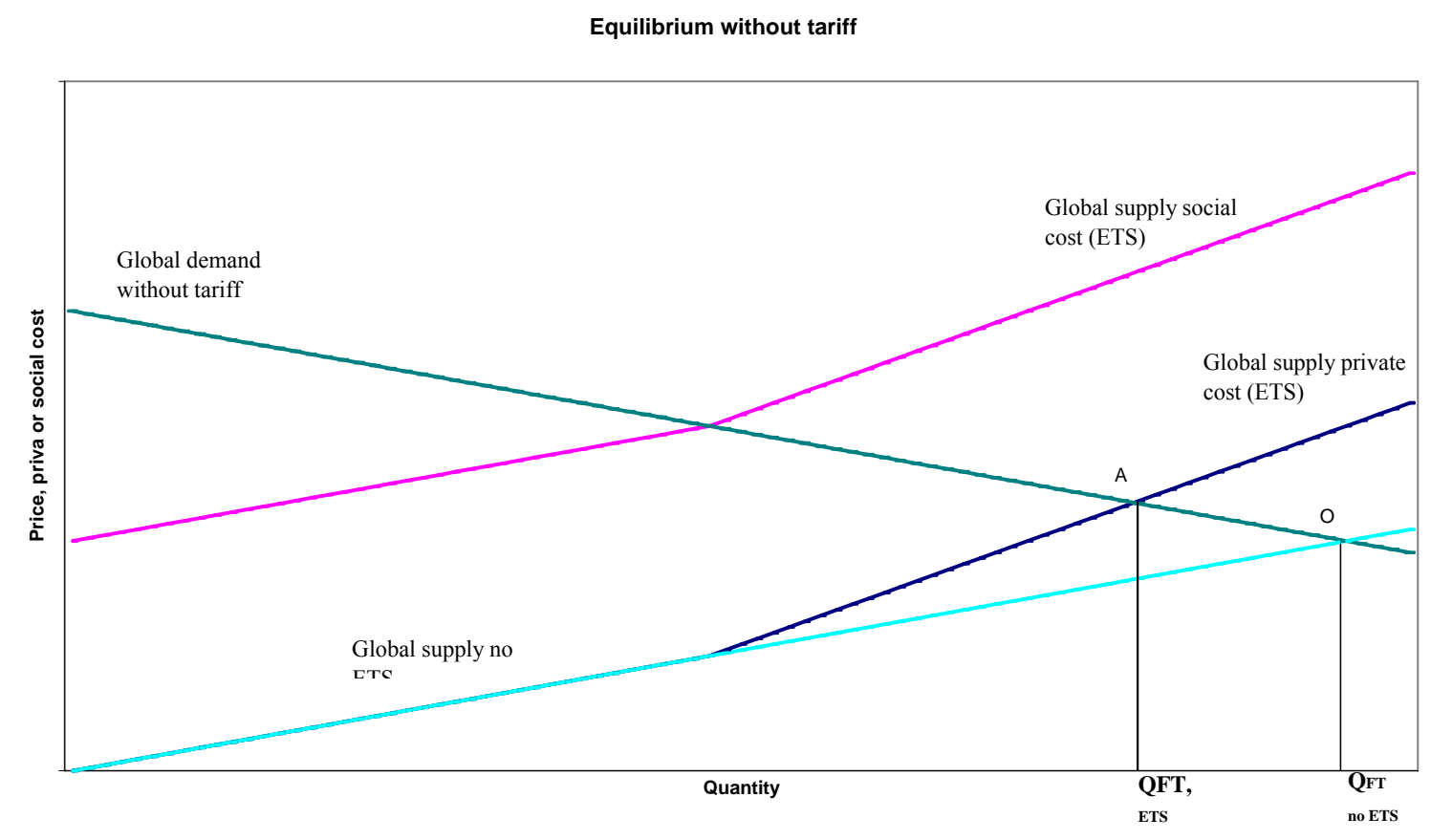

The issue at hand is what happens when the home country introduces an import tariff in addition to the ETS. The import tariff obviously reduces domestic demand and hence also global demand since it does not affect demand in the rest of the world. The import is here assumed to be specific, not ad valorem, because it is supposed to correct the externality that arises in production. Figure 2 shows the resulting equilibrium: with the introduction of the tariff the demand curve shifts down and the resulting new equilibrium price is lower than before (equilibrium shifts from point $\mathrm{A}$ to point $\mathrm{E}$ ).

The fall in the international price implies that foreign producers will produce less. Given that domestic production is limited by the ETS, global production must fall as well. The sum of domestic plus foreign consumption must thus fall as well. But this is achieved by a rise in foreign consumption (since the price falls abroad) and a fall in domestic consumption of an even larger magnitude. This shift in consumption is due to the fact that domestic and foreign consumers face a different price if there is an import tariff. 
Figure 2. Equilibrium with tariffs

Impact of tariff

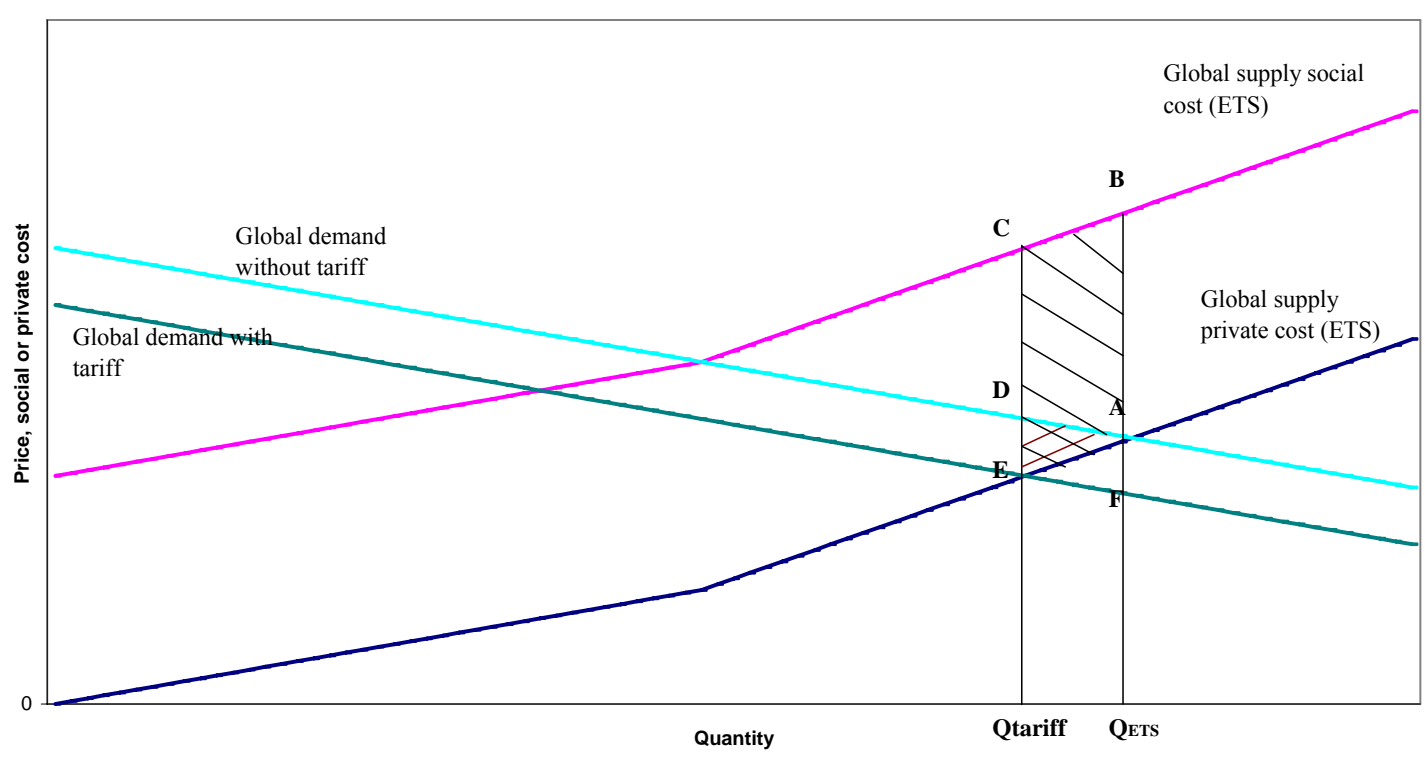

What are the welfare implications of the tariff? The standard welfare loss caused by a tariff is the usual triangle (consumer plus producer loss) enclosed by points ADE. As is well known, this welfare loss is of second order for any 'small' tariff.

In this case, however, there is also a gain due to the global externality in production. It is enclosed by the points $\mathrm{ABCE}$ (a 'rectangle' or parallelogram). The net welfare gain from imposing a tariff is given by the trapezoid enclosed by the points ABCD. It follows that a small carbon tariff must always improve global welfare.

The intuition behind this result is clear. As long as the tariff is small, the reallocation of consumption from consumers at home to consumers abroad causes only a loss of second-order importance. But the gain to global welfare from lower foreign production is of first-order importance. The remainder of the paper shows that this simple intuition remains valid in the context of a fully specified model of demand and supply of a good whose production involves an externality.

\section{The model}

This section presents a simple partial equilibrium two-country model to study the impact on trade and global welfare of the combination of a domestic carbon tax with an import tariff.

The world is divided into two actors: an importing country (or group of importing countries) and the rest of the world (RoW).

More precisely the objective of the model is to analyse the impact of a 'border' tax (or import tariff) in the importing country on world production and welfare when production involves an externality (greenhouse gas emissions). 


\subsection{The basic building blocks}

The basic building blocks of the model are standard, basic utility and production functions:

For simplicity the total (private $=$ social) cost of production is given by:

(1) $T C=T C\left(q_{s}\right)$

With the total cost function as usual twice differentiable and convex (TC' and TC' 'both strictly positive).

Production abroad is subject to potentially a different technology and cost function.

(2) $T C^{*}=T C\left(q^{*}{ }_{s}\right)$

But it has the same general property of increasing marginal costs.

Consumption of the good in question yields utility, given by:

(3) $U=U\left(q_{d}\right)$

Households abroad have the same preferences:

(4) $U^{*}=U\left(q{ }_{d}^{*}\right)$

The utility function is as usual twice differentiable and concave (U' strictly positive and U', strictly negative).

Individual utility maximisation implies that households determine consumption by equating marginal utility to the price they face in the market. Domestic consumers have to pay a price that is equal to the international price plus an import tariff (or border measure).

Denoting the international price by $\mathrm{p}$ and the import tariff by $\beta$, this implies (for the individual consumer):

(5) $p+\beta=U^{\prime}\left(q_{d}\right)$

Foreign consumers do not face an import tariff. They will set a price equal to marginal utility.

(6) $p=U^{\prime}\left(q^{*}{ }_{d}\right)$

Producers at home will set marginal cost equal to the price they face. If the importing country has a domestic carbon price, ${ }^{2}$ this implies that:

(7) $p+\beta-\varepsilon=T C^{\prime}\left(q_{s}\right)$

For future reference it will be useful to consider the case where producers abroad also face a carbon price, denoted by $\varepsilon^{*}$. Hence they will also set supply to equal marginal cost to the price adjusted for their carbon price:

(8) $p-\varepsilon^{*}=T C^{\prime}\left(q_{s}^{*}\right)$

Assuming that the EU (possibly the EU plus the US) is the importing country, the relevant case would be that $\varepsilon^{*}$ is equal to zero, but looking at the general case allows one to also analyse different constellations.

\footnotetext{
${ }^{2}$ This model considers only the case where (in equilibrium) the importing country imports the good in question. Hence, there is no need to address the question of whether the 'border tax' should also involve a rebate on exports.
} 
The receipts from carbon taxes are rebated lump sum to consumers and thus do not influence their overall budget constraint.

The only other relationship relevant for the private sector is that global supply has to equal global demand for the (possibly composite) good in question.

(9) $q_{s}+q^{*}{ }_{s}=q_{d}+q{ }_{d}$

The system of five equations (5) to (9) describes the market equilibrium, characterised by the values for the five endogenous variables (the price and the four quantities - production and consumption at home and abroad). The exogenous policy variables are the domestic carbon prices $\varepsilon$ (possibly also $\varepsilon^{*}$ ) and the import tariff, $\beta$.

The total differential of this system of equations is given by:

(10) $d p+d \beta=U^{\prime \prime}\left(q_{d}\right) d q_{d}$

(11) $d p=U^{\prime \prime}\left(q^{*}\right) d q_{d}^{*}$

(12) $d p+d \beta-d \varepsilon=T C^{\prime \prime}\left(q_{s}\right) d q_{s}$

(13) $d p-d \varepsilon^{*}=T C^{\prime \prime}\left(q_{s}^{*}\right) d q^{*}$

(14) $d q_{s}+d q{ }_{s}=d q_{d}+d q{ }_{d}$

As will become clear later, a key intermediate result for this model is the impact of an increase in the tariff, $\beta$, on the international price level. The impact of a change in the import tariff, $\beta$, on the world price (neglecting the two potential domestic carbon taxes $\varepsilon$ for the moment) can by calculated from this set of equations (see Annex for details):

(15) $\frac{d p}{d \beta}=\frac{\left(T C^{\prime \prime}\left(q_{s}\right)\right)^{-1}-\left(U^{\prime \prime}\left(q_{d}\right)\right)^{-1}}{\left(U^{\prime \prime}\left(q_{d}\right)\right)^{-1}+\left(U^{\prime \prime}\left(q_{d}^{*}\right)\right)^{-1}-\left(T C^{\prime \prime}\left(q_{s}\right)\right)^{-1}-\left(T C^{\prime \prime}\left(q^{*}{ }_{s}\right)\right)^{-1}}<0$

In a self-explanatory simplified notation $\left(\mathrm{u} \equiv-1 / \mathrm{U}^{\prime}{ }^{\prime}\left(\mathrm{q}_{\mathrm{d}}\right), \mathrm{c} \equiv 1 / \mathrm{TC} \mathrm{C}^{\prime}\left(\mathrm{q}_{\mathrm{s}}\right)\right)$, etc. this can be rewritten as:

(15), $\frac{d p}{d \beta}=\frac{-(u+c)}{u+c+u^{*}+c^{*}} \equiv \frac{-(u+c)}{\Sigma}\langle 0$

A higher import tariff leads of course to a lower world market price, but the impact is clearly partial, i.e. the absolute value of $(\mathrm{dp} / \mathrm{d} \beta)$ is smaller than one. The fraction by which an import tariff depresses the world price is given by the ratio of the slope of the domestic net supply function $(\mathrm{u}+\mathrm{c})$ divided by the global net supply function $\left(\mathrm{u}+\mathrm{c}+\mathrm{u}^{*}+\mathrm{c}^{*}\right)$.

As shown in annex 4 this fraction should be closely related to the size of the importing country relative to the rest of the world (at least in the market for the product in question). For example, if the importing country were to consist of the OECD (essentially the EU plus the US and Japan), this fraction should be close to one half since the OECD countries account for about on half of world production and demand. A concerted OECD import tariff on carbon should thus lead to a fall in the price outside the OECD by about one half of the tariff rate.

An immediate implication of equation (15)' is that introducing a carbon import tariff while keeping the domestic tax, $\varepsilon$, constant increases the price at which domestic producers can sell (on the home market). Hence domestic production will increase, which is equivalent to an 
effective increase in the domestic emissions ceiling. Formally this can be seen by using equation (15)' in the domestic supply function (12):

(12), $\frac{d q_{s}}{d \beta}=\left(\frac{d p}{d \beta}+1\right) / T C^{\prime \prime}\left(q_{s}\right)=\frac{c\left(c^{*}+u^{*}\right)}{\Sigma}>0$

The impact of a change in the domestic carbon price $\varepsilon$ on the world price can similarly be determined from the above total differential as (see annex for details):

(16) $\frac{d p}{d \varepsilon}=\frac{-\left(T C^{\prime \prime}\left(q_{s}\right)\right)^{-1}}{\left(U^{\prime \prime}\left(q_{d}\right)\right)^{-1}+\left(U^{\prime \prime}\left(q^{*}{ }_{d}\right)\right)^{-1}-\left(T C^{\prime \prime}\left(q_{s}\right)\right)^{-1}-\left(T C^{\prime \prime}\left(q^{*}{ }_{s}\right)\right)^{-1}}>0$

In the same self explanatory simplified notation, this can be re-written as:

(16) $\frac{d p}{d \varepsilon}=\frac{c}{u+c+u^{*}+c^{*}} \equiv \frac{c}{\Sigma}>0$

A higher domestic carbon tax leads of course to a higher world market price (it lowers supply at home), but the impact is clearly partial, i.e. the absolute value of $(\mathrm{dp} / \mathrm{d} \varepsilon)$ is smaller than one (and smaller than the absolute value of the impact of $\beta$ on the price).

If a higher domestic carbon tax leads to a higher world market price, it follows immediately that production abroad increases, i.e. there must be 'carbon leakage' in the parlance of the climate change literature. If carbon leakage is defined as the increase in production abroad resulting from a unit increase in the domestic carbon tax, it can be directly calculated from equation (16)' as:

(16),$d q^{*}{ }_{s}=d p c^{*}=\frac{c C^{*}}{u+c+u^{*}+c^{*}} \equiv \frac{c C^{*}}{\Sigma}>0$

In this framework a quantitative ceiling on emissions translates directly into a ceiling on (domestic) production. This implies immediately that the impact of on increase in the import tariff on the world price in the presence of an absolute ceiling on emissions like under the ETS is given by (see annex 2 for details):

(15),$\frac{d p}{d \beta_{E T S}}=\frac{-u}{u+u^{*}+C^{*}}<0$

Comparing equations (15)' and (15)'" establishes that the impact of a higher import tariff on the world market price is smaller if it is imposed by the importing country with an unchanged ceiling on emissions than if just the domestic tax on emissions is held constant.

\subsection{Global welfare}

Turning now to social welfare we have to take into account the externality generated by $\mathrm{CO}_{2}$ emissions. Social welfare is given by the sum of the utility derived from households' consumption minus production costs but plus the (negative) external effect that arises when the good is produced. For simplicity it is assumed that the external effect is equal to a constant, denoted by $\sigma$, per household, with this effect thus completely separate from consumption. In order to account for potential differences in carbon intensities (and hence technologies), it is not assumed that the production of each unit leads to the same negative external effect wherever it takes place. Instead production abroad takes place with a potentially different carbon intensity, which relative to that at home is denoted by $\gamma$. 
Furthermore there is one representative household at home and a measure $\alpha$ of households abroad (the measure of the global number of households is thus give by $(1+\alpha)$. Global social welfare is thus given by:

(17) $\mathrm{WW}=\mathrm{U}\left(\mathrm{q}_{\mathrm{d}}\right)+\mathrm{U}\left(\mathrm{q}_{\mathrm{d}}{ }_{\mathrm{d}}\right)-\mathrm{TC}\left(\mathrm{q}_{\mathrm{s}}\right)-\mathrm{TC}\left(\mathrm{q}_{\mathrm{s}}{ }_{\mathrm{s}}\right)-(1+\alpha) \sigma\left(q_{\mathrm{s}}+\gamma \mathrm{q}_{\mathrm{s}}\right)$

A social planner would maximise this global social welfare, subject, of course to the resource constraint (14) $d q_{s}+d q{ }_{s}{ }_{s}=d q_{d}+d q{ }_{d}$.

Optimal policy (from a global welfare point of view)

The impact of a change in the import tariff, $\beta$, on global social welfare can then be written as:

(19) $\left(\frac{d W W}{d \beta}\right)=\left(\frac{\partial W W}{\partial q_{d}}\right)\left(\frac{d q_{d}}{d \beta}\right)+\left(\frac{\partial W W}{\partial q^{*}{ }_{d}}\right)\left(\frac{d q_{d}^{*}}{d \beta}\right)-\left(\frac{\partial W W}{\partial q_{s}}\right)\left(\frac{d q_{s}}{d \beta}\right)-\left(\frac{\partial W W}{\partial q^{*}{ }_{s}}\right)\left(\frac{d q_{s}}{d \beta}\right)$

Clearly any evaluation of global welfare changes requires information on the marginal changes in all the four quantities:
(21) $\left(\frac{\partial W W}{\partial q_{d}}\right)=U^{\prime}\left(q_{d}\right)=p+\beta$
(22) $\left(\frac{\partial W W}{\partial q^{*}{ }_{d}}\right)=U^{\prime}\left(q_{d}^{*}\right)=p$
(23) $\left(\frac{\partial W W}{\partial q_{s}}\right)=-T C^{\prime}\left(q_{s}\right)-(1+\alpha) \sigma=-(p+\beta-\varepsilon)-(1+\alpha) \sigma$
(24) $\left(\frac{\partial W W}{\partial q^{*}{ }_{s}}\right)=-T C^{\prime}\left(q^{*}{ }_{s}\right)-\gamma(1+\alpha) \sigma=-p-\gamma(1+\alpha) \sigma$

\subsection{Welfare impact of a carbon import tariff}

The impact of a change in the import tariff, $\beta$, on global social welfare can then be written as:

$$
\left(\frac{d W W}{d \beta}\right)=(p+\beta)\left(\frac{d q_{d}}{d \beta}\right)+p\left(\frac{d q_{d}^{*}}{d \beta}\right)-(p+\beta-\varepsilon+(1+\alpha) \sigma)\left(\frac{d q_{s}}{d \beta}\right)-\left(p-\varepsilon^{*}+\gamma(1+\alpha) \sigma\right)\left(\frac{d q_{s}^{*}}{d \beta}\right)
$$

Inspection reveals that the terms in the price (p) disappear given the global resource constraint. Since the impact of a change in the import tariff on the quantities is given by the product of the marginal effect of a change in tariff on prices times the impact of prices on the quantities, equation (25) can be re-written as:

$$
\left(\frac{d W W}{d \beta}\right)=\beta\left(\frac{d q_{d}}{d p}\right)\left(\frac{d p}{d \beta}\right)-(\beta-\varepsilon+(1+\alpha) \sigma)\left(\frac{d q_{s}}{d p}\right)\left(\frac{d p}{d \beta}\right)-\left(-\varepsilon^{*}+\gamma(1+\alpha) \sigma\right)\left(\frac{d q^{*}{ }_{s}}{d p}\right)\left(\frac{d p}{d \beta}\right)
$$


This equation can be transformed recalling that the changes in the four quantities can be derived from the relevant demand and supply function (equations (9) to (12)) combined with the impact of a change in $\beta$ on the price (equation $\mathrm{xx}$ ):

$\left(\frac{d W W}{d \beta}\right)=\beta\left(\frac{1+(d \beta / d p)}{U^{\prime \prime}\left(q_{d}\right)}\right)\left(\frac{d p}{d \beta}\right)-(\beta-\varepsilon+(1+\alpha) \sigma)\left(\frac{1+(d \beta / d p)}{T C^{\prime \prime}\left(q_{x}\right)}\right)\left(\frac{d p}{d \beta}\right)-\left(-\varepsilon^{*}+\gamma(1+\alpha) \sigma\right)\left(\frac{1}{T C^{\prime \prime}\left(q^{*}{ }_{s}\right)}\right)\left(\frac{d p}{d \beta}\right)$

Or:

(27)'

$\left(\frac{d W W}{d \beta}\right)=\left\{\beta\left(\frac{1+(d \beta / d p)}{U^{\prime \prime}\left(q_{d}\right)}\right)-[\beta-\varepsilon+(1+\alpha) \sigma]\left(\frac{1+(d \beta / d p)}{T C^{\prime \prime}\left(q_{s}\right)}\right)-\left[-\varepsilon^{*}+\gamma(1+\alpha) \sigma\right]\left(\frac{1}{T C^{\prime \prime}\left(q^{*}{ }_{s}\right)}\right)\right\}\left\{\frac{d p}{d \beta}\right\}$

Using the simplified notation above and setting $\beta$ equal to zero (i.e. the derivative is evaluated around a zero import tariff), this can be rewritten as:

(28) $\left(\frac{d W W}{d \beta}\right)=\left\{[\varepsilon-(1+\alpha) \sigma] c\left(\frac{\left.\left(u *+c^{*}\right)\right)}{(u+c)}\right)-\left[\varepsilon^{*}-\gamma(1+\alpha) \sigma\right] c *\right\}\left\{\frac{(u+c)}{\Sigma}\right\}$

This result has several implications:

1. The higher the carbon price, $\varepsilon$ at home, the higher will be the impact of the imposition of an import tax on carbon on global welfare. In other words, if the importing country has a high domestic price of carbon the more it is likely that global welfare will increase if the importing country also imposes an import tariff on carbon.

2. The opposite holds true for the carbon price abroad: if the rest if the world has a high domestic price of carbon (high $\varepsilon^{*}$ ), the more it is likely that global welfare will fall if the importing country imposes an import tariff on carbon.

3. If the home carbon tax is just equal to the externality (from domestic consumption), i.e. $\varepsilon=(1+\alpha) \sigma$, the imposition of a carbon import tariff by the importing country always increases global welfare as long as the carbon tax in the rest of the world is below the externality there, i.e. as long as: $\varepsilon^{*} \leq \gamma(1+\alpha) \sigma$.

4. In general a higher relative intensity of carbon abroad $(\gamma>1)$ increases the desirability of an import tariff imposed by the importing country because a border tax shifts production to the importing country, which in this case leads to lower environmental costs.

5. In the symmetric case, i.e. if both countries have the same marginal costs and marginal utilities $\left(\mathrm{u}=\mathrm{u}^{*}\right.$ and $\left.\mathrm{c}=\mathrm{c}^{*}\right)$, the result depends only on the difference in the two domestic carbon taxes $\left(\varepsilon\right.$ versus $\left.\varepsilon^{*}\right)$ and the difference in relative carbon intensity: $\operatorname{Sign}\left(\frac{d W W}{d \beta}\right)=\operatorname{sign}\left\{\left[\varepsilon-\varepsilon^{*}\right]+[(\gamma-1)(1+\alpha) \sigma] c\right\}$. This implies that the imposition of an import tariff by the importing country would increase world welfare even if both countries have the same domestic price of carbon, but the foreign country has a higher carbon intensity of production. 
The level of the import tariff by the importing country which maximises global welfare, given the domestic carbon prices at home, $\varepsilon$, and potentially also abroad $\varepsilon^{*}$, can be calculated from the condition that:

(29) $\beta_{\max \text { globalwelfare }} \frac{u^{*}+c^{*}}{u c}=[\varepsilon-(1+\alpha) \sigma]\left(\frac{\left(u^{*}+c^{*}\right)}{c(u+c)}\right)-\left[\varepsilon^{*}-\gamma(1+\alpha) \sigma\right]\left(\frac{1}{c^{*}}\right)$

The same four considerations apply here as well. In particular in the symmetric case (same utility and cost functions plus same country size) the magnitude of the import tariff which maximises global welfare is given by:

$$
\beta_{\max \text { globalwelfareu }=u^{*}, c=c^{*}}=\left\{[\varepsilon-(1+\alpha) \sigma]-\left[\varepsilon^{*}-\gamma(1+\alpha) \sigma\right]\right\}\left(\frac{u}{(u+c)}\right)
$$

The import tariff that maximises global welfare is thus equal to a fraction of the difference between the gap between the externality and the domestic carbon tax at home and the same gap abroad. The obvious implication is that if both countries have proper carbon pricing, the optimal import tariff is equal to zero. For the special case of $\gamma=1$ (same carbon intensity) and $\varepsilon^{*}=0$ (no carbon pricing abroad), the tariff that is optimal from a global point of view is equal to a fraction of the domestic carbon price:

$$
\beta_{\max \text { globalwelfareu }=u^{*}, c=c^{*}, \gamma=1}=\varepsilon\left(\frac{u}{(u+c)}\right)
$$

The size of the fraction depends on the (absolute values of the) slope of the demand function relative to that of the supply function. This implies that the optimal import tariff will not create a totally 'level' playing field in the sense that domestic producers will still be at a 'competitive disadvantage' relative to foreign producers after the imposition of the optimal import tariff. It is apparent that a higher value of $\gamma$ (a higher relative carbon intensity of production abroad) justifies a higher import tariff.

\subsection{Optimal domestic carbon tax}

The analysis so far has taken the domestic carbon tax as given. However, this need not be the case. An enlightened home government should choose both the domestic carbon price and the import tariff in an optimal manner. In order to discuss this choice, one needs to calculate the impact of a change in the domestic carbon tax, $\varepsilon$, on global social welfare. The starting point can again be the total differential (25) of the equation describing global welfare.

The impact of a change in the domestic carbon tax, $\varepsilon$, on global social welfare can then be written as:

(32) $\left(\frac{d W W}{d \varepsilon}\right)=\left(\frac{\partial W W}{\partial q_{d}}\right)\left(\frac{d q_{d}}{d \varepsilon}\right)+\left(\frac{\partial W W}{\partial q^{*}{ }_{d}}\right)\left(\frac{d q^{*}{ }_{d}}{d \varepsilon}\right)-\left(\frac{\partial W W}{\partial q_{s}}\right)\left(\frac{d q_{s}}{d \varepsilon}\right)-\left(\frac{\partial W W}{\partial q^{*}{ }_{s}}\right)\left(\frac{d q_{s}^{*}}{d \varepsilon}\right)$

Using again the set of equations that describe the marginal impact on global welfare of a change in all the four quantities in terms of prices and taxes, this can be rewritten as:

$$
\left(\frac{d W W}{d \varepsilon}\right)=(p+\beta)\left(\frac{d q_{d}}{d \varepsilon}\right)+p\left(\frac{d q_{d}^{*}}{d \varepsilon}\right)-(p+\beta-\varepsilon+(1+\alpha) \sigma)\left(\frac{d q_{s}}{d \varepsilon}\right)-\left(p-\varepsilon^{*}+\gamma(1+\alpha) \sigma\right)\left(\frac{d q_{s}^{*}}{d \varepsilon}\right)
$$

Inspection reveals that the terms in the price (p) disappear given the global resource constraint. Since the impact of a change in the domestic carbon tax on the quantities is given by the product 
of the marginal effect of a change in the tax on the price times the impact of the price on the quantities (derived from the relevant demand and supply function (equations $\mathrm{xx}$ to $\mathrm{xx}$ )), this equation can be re-written as:

$\left(\frac{d W W}{d \varepsilon}\right)=\beta\left(\frac{1}{U^{\prime \prime}\left(q_{d}\right)}\right)\left(\frac{d p}{d \varepsilon}\right)-(\beta-\varepsilon+(1+\alpha) \sigma)\left(\frac{1-(d \varepsilon / d p)}{T C^{\prime \prime}\left(q_{s}\right)}\right)\left(\frac{d p}{d \varepsilon}\right)-\left(-\varepsilon^{*}+\gamma(1+\alpha) \sigma\right)\left(\frac{1}{T C^{\prime \prime}\left(q^{*}{ }_{s}\right)}\right)\left(\frac{d p}{d \varepsilon}\right)$

This equation can be simplified using the notation from above:

(34)' $\left(\frac{d W W}{d \varepsilon}\right)=\left\{\beta u+(\beta-\varepsilon+(1+\alpha) \sigma) c\left[c^{*}+u+u^{*}\right]-\left(-\varepsilon^{*}+\gamma(1+\alpha) \sigma\right) c *\right\}\left(\frac{c}{\Sigma}\right)$

If one considers the impact of the introduction (or increase in) of a domestic carbon tax on global welfare, it makes sense to assume that there is no import tax $(\beta=0)$.

In this case several conclusions follow immediately:

For the case of equality in technology, or rather identical slopes of the supply functions $\left(\mathrm{c}=\mathrm{c}^{*}\right)$, it follows that:

(35) $\left(\frac{d W W}{d \varepsilon}\right)=\left\{(-\varepsilon+(1+\alpha) \sigma)\left(1+\frac{u+u^{*}}{c}\right)-\left(-\varepsilon^{*}+\gamma(1+\alpha) \sigma\right)\right\}\left(\frac{1}{\Sigma}\right)$

(35) $\left(\frac{d W W}{d \varepsilon}\right)=\left\{(-\varepsilon+(1+\alpha) \sigma)\left(1+\frac{u+u^{*}}{c}\right)-\left(-\varepsilon^{*}+\gamma(1+\alpha) \sigma\right)\right\}\left(\frac{1}{\Sigma}\right)$

And thus an increase in the domestic tax on carbon will always increase global welfare if both $\varepsilon$ and $\varepsilon^{*}$ are initially zero and the relative carbon intensity abroad is at most equal to that at home $\gamma<1$. In the case of equal technology the domestic carbon price that maximises global welfare can be derived by setting the RHS of this last equation to zero. The resulting expression can be simplified to:

(36) $\varepsilon_{\max \text { globalwelfare }}=(1+\alpha) \sigma+\left(\varepsilon^{*}-\gamma(1+\alpha) \sigma\right)\left(\frac{c}{c+u+u^{*}}\right)$

For the case of no domestic tax abroad $\left(\varepsilon^{*}=0\right)$, this can be rewritten as:

$$
\varepsilon_{\text {max globalwelfare }}=(1+\alpha) \sigma\left(1-\gamma \frac{c}{c+u+u^{*}}\right)
$$

The intuition behind this result is clear: the optimal domestic carbon price is equal to the domestically generated distortion (given the carbon intensity at home) minus a fraction of the distortion given the carbon intensity $\gamma$ abroad (with the fraction given by $\mathrm{c} /\left(\mathrm{c}+\mathrm{u}+\mathrm{u}^{*}\right)$. The higher the foreign distortion (a high value of $\gamma$ ) the less it makes sense to impose a domestic carbon tax because this leads at least to a partial shift in production abroad, which might not be good for global welfare if the carbon intensity abroad is higher than the one at home.

Inspection of the last equation reveals that the importing country cannot improve global welfare anymore through a positive domestic carbon tax if:

$$
\gamma_{\varepsilon \max \text { globalwelfare }=0} \geq \frac{c+u+u^{*}}{c}=1+\frac{u+u^{*}}{c}
$$


In this case it would be better for global welfare that the importing country subsidises domestic production. This would lead to a shift in aggregate global production, but global emissions would be lower because the shift towards production at home, which is much less carbonintensive than production at home (under this condition), would lead to lower overall emissions.

A higher carbon price abroad would obviously also motivate (from a global welfare point of view) a higher carbon price at home.

\subsection{Optimal choice of both policy instruments}

Finally, one can consider the case of an altruistic country that sets both (domestic) policy instruments in order to maximise global welfare. Such a country would set both instruments according to:

$$
\begin{aligned}
& \beta_{\max \text { globalwelfareu }=u^{*}, c=c^{*}}=\left\{[\varepsilon-(1+\alpha) \sigma]-\left[\varepsilon^{*}-\gamma(1+\alpha) \sigma\right]\right\}\left(\frac{u}{(u+c)}\right) \\
& 0=\beta\left(\frac{c}{u}\right)+[\beta-\varepsilon+(1+\alpha) \sigma]\left(1+\frac{u+u^{*}}{c}\right)-\left(\gamma(1+\alpha) \sigma-\varepsilon^{*}\right)
\end{aligned}
$$

Solving the second equation for the optimal domestic carbon tax and substituting the result into the first equation yields an expression of the optimal (from a global point of view) tariff in terms of the parameters of the model:

$\beta_{\text {max globalwelfareuonboth }}=\left\{\left(\frac{c}{c+u+u^{*}}\right)\left[\left[\varepsilon^{*}-\gamma(1+\alpha) \sigma\right]+\beta\left(\frac{c}{u}\right)\right]+\beta-\left[\varepsilon^{*}-\gamma(1+\alpha) \sigma\right]\right\}\left(\frac{u}{(u+c)}\right)$

In a simplified form, this can be re-written as:

$$
\beta_{\text {max globalwelffareuonboth }}=\{\gamma(1+\alpha) \sigma-\varepsilon *\}\left(\frac{u}{c}\right)
$$

It follows that when the importing country concentrates on global welfare in setting both policy variables, the 'optimal' import tariff is proportional to the distortion abroad $\left[\gamma(1+\alpha) \sigma-\varepsilon^{*}\right]$, which is always positive as long as the foreign country does not impose proper carbon pricing. This general result is independent of the shapes of the supply and demand functions.

Substituting this last equation into the equation that determines the optimal domestic carbon tax yields:

$$
\varepsilon_{\max \text { globalwelfareuonboth }}=\{\gamma(1+\alpha) \sigma-\varepsilon *\}\left(\frac{u}{c}\right)+(1+\alpha) \sigma
$$

Or:

(42)' $\varepsilon_{\max \text { globalwelfareuonboth }}=\left(\beta_{\max \text { globalwelfareuonboth }}+(1+\alpha) \sigma\right)=\{\gamma(1+\alpha) \sigma-\varepsilon *\}\left(\frac{u}{c}\right)+(1+\alpha) \sigma$ 
It follows that the optimal import tariff is always smaller than the (optimal) domestic carbon tax. The difference is given by the negative global externality that arises through domestic production $[(1+\alpha) \sigma]$.

$[(1+\alpha) \sigma]$.

\section{Quantitative ceilings (ETS)}

The welfare impact of an import tariff in the presence of an emissions trading system (ETS) that fixes a ceiling on domestic supply can be calculated from the total differential of global welfare (in this case the domestic carbon price becomes endogenous and equivalent to the price of a domestic allowance under an auction system):

(19)' $\left(\frac{d W W}{d \beta}\right)_{E T S}=\left(\frac{\partial W W}{\partial q_{d}}\right)\left(\frac{d q_{d}}{d \beta}\right)+\left(\frac{\partial W W}{\partial q^{*}{ }_{d}}\right)\left(\frac{d q^{*}{ }_{d}}{d \beta}\right)-\left(\frac{\partial W W}{\partial q^{*}{ }_{s}}\right)\left(\frac{d q^{*}}{d \beta}\right)$

Given that the quantity produced at home $\left(\mathrm{q}_{\mathrm{s}}\right)$ is capped by the ETS this can be simplified to:

(25)' $^{\prime}\left(\frac{d W W}{d \beta}\right)_{E T S}=(p+\beta)\left(\frac{d q_{d}}{d \beta}\right)+p\left(\frac{d q_{d}^{*}}{d \beta}\right)-\left(p-\varepsilon^{*}+\gamma(1+\alpha) \sigma\right)\left(\frac{d q^{*}{ }_{s}}{d \beta}\right)$

Inspection reveals that the terms in the price (p) disappear given the global resource constraint. Since the impact of a change in the import tariff on the quantities is given by the product of the marginal effect of a change in tariff on prices times the impact of prices on the quantities, equation (25)' can be simplified to:

(26)' $\left(\frac{d W W}{d \beta}\right)_{E T S}=\beta\left(\frac{d q_{d}}{d p}\right)\left(\frac{d p}{d \beta}\right)-\left(-\varepsilon^{*}+\gamma(1+\alpha) \sigma\right)\left(\frac{d q_{s}^{*}}{d p}\right)\left(\frac{d p}{d \beta}\right)$

A first result is immediate if one considers the benchmark case of $\varepsilon^{*}=0$. In this case it is always in the interest of global welfare to introduce an import tariff (i.e. an increase of $\beta$ from zero to some positive value) since under these conditions using (15), $\frac{d p}{d \beta_{E T S}}=\frac{-u}{u+u^{*}+C^{*}}\langle 0$ yields immediately:

$\left(\frac{d W W}{d \beta}\right)_{E T S, \beta \approx 0, \varepsilon^{*}=0}=-\gamma(1+\alpha) \sigma\left(\frac{d q_{s}^{*}}{d p}\right)\left(\frac{d p}{d \beta}\right)=\gamma(1+\alpha) \sigma c * \frac{u}{c^{*}+u+u^{*}}$

The intuition behind this result is clear. If the tariff is equal to zero the reallocation of consumption from consumers at home to consumers abroad causes only a loss of second-order importance. But the gain to global welfare from lower foreign production is of first-order importance if the rest of the world does not price carbon properly (i.e. if $\varepsilon^{*}\langle\gamma(1+\alpha) \sigma)$. This is exactly the effect shown in the figure 2 of section 1 above.

For the general case of $\beta$ positive, equation (26)' can be transformed recalling that the changes in the two quantities can be derived from the relevant demand and supply function (equations (10) and (13)): 


$$
\left(\frac{d W W}{d \beta}\right)_{E T S}=\beta\left(\frac{1+(d \beta / d p)}{U^{\prime \prime}\left(q_{d}\right)}\right)\left(\frac{d p}{d \beta}\right)-\left(-\varepsilon^{*}+\gamma(1+\alpha) \sigma\right)\left(\frac{1}{T C^{\prime \prime}\left(q^{*}{ }_{s}\right)}\right)\left(\frac{d p}{d \beta}\right)
$$

Substituting out for the supply and demand function as well as the impact of the tariff on the international price, this can be rewritten as:

$$
\text { (27)' }\left(\frac{d W W}{d \beta}\right)_{E T S}=\left\{\beta u\left(\frac{u^{*}+c^{*}}{u+u^{*}+c^{*}}\right)-\left[-\varepsilon^{*}+\gamma(1+\alpha) \sigma\right] c^{*}\right\}\left\{\frac{d p}{d \beta}\right\}
$$

This expression will be positive as long as the expression in the first curly brackets is negative given that the expression in the second curly brackets (impact of a change in $\beta$ on the price (equation (15)'") is always negative.

The tariff that maximises global welfare under the condition that the ETS at home fixes domestic production is thus given by the condition that:

$$
\beta_{\text {optimalETS }} u\left(\frac{u^{*}+c^{*}}{u+u^{*}+c^{*}}\right)=\left[-\varepsilon^{*}+\gamma(1+\alpha) \sigma\right] c^{*}
$$

Or:

$$
\beta_{\text {optimalETS }}=\left[-\varepsilon^{*}+\gamma(1+\alpha) \sigma\right] c *\left(\frac{u+u^{*}+C^{*}}{u\left(u^{*}+C^{*}\right)}\right)
$$

This result has several implications:

1) Not surprisingly, the optimal tariff is higher the higher is $\gamma$, i.e. the carbon intensity of production abroad. However, the optimal tariff remains positive even if the carbon intensity abroad is much lower than at home $(\gamma<<1)$ - provided of course that the foreign carbon price is insufficient to cover the externality abroad.

2) A higher slope of supply function abroad or equivalently a larger production base abroad, $\mathrm{c}^{*}$, also leads to a higher optimal tariff.

3) A higher slope of the demand curve at home or a larger share of the home country in world income, $\mathrm{u}$ (relative to $\mathrm{u}^{*}$ ), implies a lower optimal tariff.

4) Obviously a higher carbon tax abroad $\left(\varepsilon^{*}\right)$ implies a lower optimal tariff and if the foreign country imposes a carbon tax which just offsets the externality the rationale for a carbon tariff disappears.

5) The level of the domestic emissions cap (and hence the level of the implicit domestic carbon price, $\varepsilon$ ) does not directly influence the optimal tariff.

\section{Concluding remarks}

The main purpose of this paper is to provide an evaluation of the economic impact of 'border measures' in climate change policy from a global welfare point of view. Most of the literature has focused on two related, but separate issues which concern only national welfare; namely 'carbon leakage' and the loss of competitiveness of energy-intensive industries in countries that introduce limits on emissions. However, climate change policy is motivated in the first instance by a concern for global welfare. Hence one should not look at these issues from a national or regional point of view. 
Moreover, addressing these issues from an economic welfare point of view means that one cannot look exclusively at the impact of any one measure on the amount of $\mathrm{CO}_{2}$ emissions, but also at the cost of production and consumer welfare.

The results obtained with a simple model are straightforward and intuitively clear. Overall, as one would expect, an import tariff improves global welfare because this transfers carbon pricing, at least partially, via trade flows, even to those parts of the world whose governments have so far refrained from imposing any domestic measures. The optimal level of the tariff rate (from a global welfare point of view) depends on many parameters, such as the elasticities of demand and supply, but the key parameter remains the external impact of emissions. The model also shows that the rationale for the imposition of a carbon import tariff remains even if carbon efficiency abroad is higher than at home.

This paper has abstracted from the inter-temporal aspects in inherent in the natural resource extraction problem emphasised by Sinn (2008). However, the general flavour of the results, namely that global welfare should be improved by complementing a domestic 'cap and trade' system with an tariff on the carbon content of imports, should not be affected. Further research on this aspect would, however, be useful taking into account also of the fact that carbon capture and storage technologies can break the direct link between the use of fossil fuels and the release of $\mathrm{CO} 2$ into the atmosphere. 


\section{References}

Demailly, D. and P. Quirion (2005), "Leakage from climate policies and border-tax adjustment: Lessons from a geographic model of the cement industry", CESifo Venice Summer Institute.

General Agreement on Tariffs and Trade (GATT) (1970), Working Party Report on Border Tax Adjustments, GATT Document L/3464 (http://www.worldtradelaw.net/reports/gattpanels/bordertax.pdf).

Grossman, G.M. (1980), "Border Tax Adjustments: Do they distort trade?", Journal of International Economics, 10.

Hufbauer, Gary Clyde, Steve Charnovitz and Jisun Kim (2009 "Global Warming and the World Trading System”, Peterson Institute for International Economics, Washington, D.C.

Johnson, H.G. and M. Krauss (1970), "Border Taxes, Border Tax Adjustment, Comparative Advantage and the Balance of Payments", Canadian Journal of Economics, November.

Majocchi, A. and M. Missaglia (2002), "Environmental taxes and border tax adjustment", Societa Italiana Economia pubblica (SIEP), Working Paper No. 127/2002.

Mathiesen, L. and O. Maestad (2002), "Climate policy and steel industry: Achieving global emission reductions by an incomplete climate agreement", Discussion Papers 20/02, Norwegian School of Economics and Business Administration, Bergen.

McKibben, W.J. and P. Wilcoxen (2008), "The Economic and Environmental Effects of Border Tax Adjustments for Climate Policy", Brookings Global Economy and Development Conference, Brookings Institution, Washington, D.C.

Quick, R. (2008), "Border Tax Adjustment in the Context of Emission Trading: Climate Protection or Naked Protectionism", Global Trade and Customs Journal, Kluwer Law International.

Sinn, Hans-Werner (2008) "Public policies against global warming: a supply side approach"

Journal International Tax and Public Finance, Volume 15, Number 4 / August, 2008, Pages 360-394.

Veenendaal, P. and T. Manders (2008), "Border tax adjustment and the EU-ETS, a quantitative assessment", CPB Document No. 171, Central Planning Bureau, The Hague.

World Bank (2008), "International Trade and Climate Change: Economic, Legal and Institutional Perspectives", Washington, D.C. 


\section{Annexes. Details of calculations}

Annex 1 Calculation of the impact of changes in the import tariff, $\beta$, and of the domestic carbon tax, $\varepsilon$, on the international price. The starting point is the total differential of the five equations describing the equilibrium in all markets:

$\mathrm{A}(10)^{\prime}(d p+d \beta) / U^{\prime \prime}\left(q_{d}\right)=d q_{d}$

$\mathrm{A}(11), d p / U^{\prime \prime}\left(q{ }^{*}{ }_{d}\right)=d q{ }^{*}{ }_{d}$

$\mathrm{A}(12)^{\prime}(d p+d \beta-d \varepsilon) / T C^{\prime \prime}\left(q_{s}\right)=d q_{s}$

$\mathrm{A}(13),(d p-d \varepsilon *) / T C^{\prime \prime}\left(q *{ }_{s}\right)=d q *{ }_{s}$

The global resource constraint (14) implies that the sum of the first two terms (change in global demand) must be equal to the sum of the last two terms (change in global supply):

$\left[(d p+d \beta-d \varepsilon) / T C^{\prime \prime}\left(q_{s}\right)\right]+\left[\left(d p-d \varepsilon^{*}\right) / T C^{\prime \prime}\left(q^{*}{ }_{s}\right)\right]=d q_{s}+d q^{*}{ }_{s}=$ $\left[(d p+d \beta) / U^{\prime \prime}\left(q_{d}\right)\right]+\left[d p / U^{\prime \prime}\left(q^{*}{ }_{d}\right)\right]=d q_{d}+d q^{*}{ }_{d}$

Or:

$\left[(d p+d \beta-d \varepsilon) / T C^{\prime \prime}\left(q_{s}\right)\right]+\left[\left(d p-d \varepsilon^{*}\right) / T C^{\prime \prime}\left(q^{*}{ }_{s}\right)\right]=$ $\left[(d p+d \beta) / U^{\prime \prime}\left(q_{d}\right)\right]+\left[d p / U^{\prime \prime}\left(q^{*}{ }_{d}\right)\right]$

Or:

$$
\begin{aligned}
& d p\left[\left(T C^{\prime \prime}\left(q_{s}\right)\right)^{-1}+\left(T C^{\prime \prime}\left(q_{s}^{*}\right)\right)^{-1}-\left(U^{\prime \prime}\left(q_{d}\right)\right)^{-1}-\left(U^{\prime \prime}\left(q_{d}^{*}\right)\right)^{-1}\right]= \\
& d \varepsilon^{*}\left[\left(T C^{\prime \prime}\left(q_{s}^{*}\right)\right)^{-1}\right]+d \varepsilon\left[\left(T C^{\prime \prime}\left(q_{s}\right)\right)^{-1}\right]-d \beta\left[\left(T C^{\prime \prime}\left(q_{s}\right)\right)^{-1}-\left(U^{\prime \prime}\left(q_{d}\right)\right)^{-1}\right]
\end{aligned}
$$

The result for $\mathrm{dp} / \mathrm{d} \beta$ (and $\mathrm{d} \varepsilon / \mathrm{d} \beta$ ) is then immediate.

\section{Annex 2. Emissions trading system}

With a fixed limit on domestic production, the impact of an import tariff is somewhat different. With an ETS-like limit $\left(\mathrm{dq}_{\mathrm{s}}=0\right)$, the system becomes:

A2 (10) $d p+d \beta=U^{\prime \prime}\left(q_{d}\right) d q_{d}$

A2 (11) $d p=U^{\prime \prime}\left(q^{*}{ }_{d}\right) d q^{*}$

A2 (12) $d p+d \beta-d \varepsilon=0$

A2 (13) $d p-d \varepsilon^{*}=T C^{\prime \prime}\left(q^{*}{ }_{s}\right) d q_{s}$

A2 (14) $d q^{*}{ }_{s}=d q_{d}+d q{ }_{d}$

With $\varepsilon$ now endogenous (and $\mathrm{q}_{\mathrm{s}}$ exogenous because fixed by the ETS), equation 12 expresses the intuition that the sum of the change in the price and the import tariff must equal the change in the domestic carbon price, $\varepsilon$, in order to keep domestic production (and hence domestic emissions) constant. 
A2

$\left[\left(d p-d \varepsilon^{*}\right) / T C^{\prime \prime}\left(q_{s}^{*}\right)\right]=$

$\left[(d p+d \beta) / U^{\prime \prime}\left(q_{d}\right)\right]+\left[d p / U^{\prime \prime}\left(q^{*}{ }_{d}\right)\right]$

A2

$d p\left[\left(T C^{\prime \prime}\left(q_{s}^{*}\right)\right)^{-1}-\left(U^{\prime \prime}\left(q_{d}\right)\right)^{-1}-\left(U^{\prime \prime}\left(q_{d}^{*}\right)\right)^{-1}\right]=$

$d \varepsilon^{*}\left[\left(T C^{\prime \prime}\left(q_{s}^{*}\right)\right)^{-1}\right]+d \beta\left[\left(U^{\prime \prime}\left(q_{d}\right)\right)^{-1}\right]$

This implies:

A2

$d p=$

$\frac{d \varepsilon^{*}\left[\left(T C^{\prime \prime}\left(q_{s}^{*}\right)\right)^{-1}\right]}{\left[\left(T C^{\prime \prime}\left(q_{s}{ }_{s}\right)\right)^{-1}-\left(U^{\prime \prime}\left(q_{d}\right)\right)^{-1}-\left(U^{\prime \prime}\left(q_{d}^{*}\right)\right)^{-1}\right]^{+}} \frac{d \beta\left[\left(U^{\prime \prime}\left(q_{d}\right)\right)^{-1}\right]}{\left[\left(T C^{\prime \prime}\left(q_{s}^{*}\right)\right)^{-1}-\left(U^{\prime \prime}\left(q_{d}\right)\right)^{-1}-\left(U^{\prime \prime}\left(q^{*}{ }_{d}\right)\right)^{-1}\right]}$

Which implies:

A2

$\frac{d p}{d \beta_{E T S}}=\frac{-u}{u+u^{*}+c^{*}} \equiv \frac{-u}{\Sigma-c}<0$

With domestic supply fixed (by the ETS), it follows that the only impact an import tariff can have is via lower domestic consumption, which in turn implies a lower price globally.

Given equation A2 (12), this implies that an increase in the tariff lowers the domestic tax on carbon:

A2

${\frac{d p}{d \varepsilon_{E T S}}}_{E}=1+{\frac{d p}{d \varepsilon_{E T S}}}_{\text {ETS }}=1+\frac{-u}{u+u^{*}+C^{*}}=\frac{c^{*}+u^{*}}{u+u^{*}+C^{*}}\langle 1$

\section{Annex 3 Carbon leakage}

A unit increase in the domestic carbon price leads to an increase in the world market price and hence an increase in production abroad equal to:

A3 (1) or (16),$d q^{*}{ }_{s}=d p c^{*}=\frac{c c^{*}}{u+c+u^{*}+c^{*}} \equiv \frac{c c^{*}}{\Sigma}>0$

At home production falls, with the fall determined by the supply function (12):

A3 (2) $d q_{s}=c(d p-d \varepsilon)=c\left[\frac{d p}{d \varepsilon}-1\right] d \varepsilon=\frac{\left.-c\left(c^{*}+u+u^{*}\right)\right)}{u+c+u^{*}+c^{*}} d \varepsilon\langle 0$

One could define 'carbon leakage' in relative terms, i.e. as the absolute value of the ratio (increase in foreign production)/(fall in domestic production). This would be equal to: 
$\mathrm{A} 3(3) \frac{d q_{s}^{*}}{-d q_{s}}=\frac{c^{*}}{\left.\left(c^{*}+u+u^{*}\right)\right)}=\frac{1}{1+\left(u+u^{*}\right) / c^{*}}<1$

Leakage will thus be always partial and it depends on the size of the sum of the slopes of the demand curves relative to the slope of the supply curve abroad. The less elastic demand relative to supply (i.e. the smaller $\mathrm{u}$ and $\mathrm{u}^{*}$ relative to $\mathrm{c}^{*}$ ) the more important will be leakage.

\section{Annex 4 Country size}

As mentioned in the main text the demand and supply functions are strictly valid only for the individual consumer and producer. However, what matters for the global equilibrium is the absolute amounts produced and consumed. However, taking into account differences in country would not affect the conclusions, only the way the country-wide demand and supply functions are interpreted:

If preferences are homothetic demand will just be proportional to the income of consumers (within any country). Thus one can normalize the number and income of consumers in the home country to one. There are $\alpha$ consumers abroad and their purchasing power per capita can be indicated by $\eta$. This is implies that the overall demand of the foreign country is given by equation (5) multiplied by the product of these two parameters. One interesting case would be that $\alpha \eta$ equals one. In this case the overall income of consumers in both 'countries' would be equal, which is not too far from reality if one takes the OECD group as the 'home' country since the OECD countries account for slightly more than $50 \%$ of global GDP. (In this case one would of course have $\alpha>1$ and $\eta<1$.

Similarly, the supply functions of each individual firms should be multiplied by the number (and productivity) of firms within in each country. Using again the normalisation that there is one production unit at home one can parameterise the (relative) size of the foreign country by a parameter, $\mu$.

The total differential of this system of equations is then given by:

(10) $d p+d \beta=U^{\prime \prime}\left(q_{d}\right) d q_{d}$

(11) $d p=\alpha \eta U^{\prime \prime}\left(q^{*}{ }_{d}\right) d q{ }_{d}$

(12) $d p+d \beta-d \varepsilon=T C^{\prime \prime}\left(q_{s}\right) d q_{s}$

(13) $d p-d \varepsilon^{*}=\mu T C^{\prime \prime}\left(q^{*}{ }_{s}\right) d q{ }^{*}$

(14) $d q_{s}+d q_{s}^{*}=d q_{d}+d q{ }_{d}$ 


\section{CESifo Working Paper Series}

for full list see www.cesifo-group.org/wp

(address: Poschingerstr. 5, 81679 Munich, Germany, office@cesifo.de)

2729 Luca Di Corato and Michele Moretto, Investing in Biogas: Timing, Technological Choice and the Value of Flexibility from Inputs Mix, July 2009

2730 Gilad D. Aharonovitz, Nathan Skuza and Faysal Fahs, Can Integrity Replace Institutions? Theory and Evidence, July 2009

2731 Michele Moretto and Sergio Vergalli, Managing Migration through Conflicting Policies: an Option-theory Perspective, July 2009

2732 Volker Nitsch, Fly or Cry: Is Airport Noise Costly?, July 2009

2733 Francesco Cinnirella and Joachim Winter, Size Matters! Body Height and Labor Market Discrimination: A Cross-European Analysis, July 2009

2734 Samuel Bowles and Sandra Polanía Reyes, Economic Incentives and Social Preferences: A Preference-based Lucas Critique of Public Policy, July 2009

2735 Gary Burtless, Lessons of the Financial Crisis for the Design of National Pension Systems, July 2009

2736 Helmuth Cremer, Firouz Gahvari and Pierre Pestieau, Fertility, Human Capital Accumulation, and the Pension System, July 2009

2737 Hans Jarle Kind and Frank Stähler, Market Shares in Two-Sided Media Industries, July 2009

2738 Pamela Campa, Alessandra Casarico and Paola Profeta, Gender Culture and Gender Gap in Employment, August 2009

2739 Sebastian Gechert, Supplementary Private Health Insurance in Selected Countries: Lessons for EU Governments?, August 2009

2740 Leif Danziger, Endogenous Monopsony and the Perverse Effect of the Minimum Wage in Small Firms, August 2009

2741 Yan Dong and John Whalley, A Third Benefit of Joint Non-OPEC Carbon Taxes: Transferring OPEC Monopoly Rent, August 2009

2742 Valentina Bosetti, Carlo Carraro and Massimo Tavoni, Climate Change Mitigation Strategies in Fast-Growing Countries: The Benefits of Early Action, August 2009

2743 Christina Felfe, The Willingness to Pay for Job Amenities: Evidence from Mothers' Return to Work, August 2009 
2744 Jörg Franke, Christian Kanzow, Wolfgang Leininger and Alexandra Väth, Effort Maximization in Asymmetric N-Person Contest Games, August 2009

2745 Bruno S. Frey and Paolo Pamini, Making World Heritage Truly Global: The Culture Certificate Scheme, August 2009

2746 Frank N. Caliendo, Is Social Security behind the Collapse of Personal Saving?, August 2009

2747 Caterina Liesegang and Marco Runkel, Corporate Income Taxation of Multinationals and Fiscal Equalization, August 2009

2748 Chrysovalantou Milliou and Apostolis Pavlou, Upstream Horizontal Mergers and Efficiency Gains, August 2009

2749 Rüdiger Pethig and Christian Wittlich, Interaction of Carbon Reduction and Green Energy Promotion in a Small Fossil-Fuel Importing Economy, August 2009

2750 Kai Carstensen, Oliver Hülsewig and Timo Wollmershäuser, Monetary Policy Transmission and House Prices: European Cross-country Evidence, August 2009

2751 Olaf Posch, Explaining Output Volatility: The Case of Taxation, August 2009

2752 Beatrice Scheubel, Daniel Schunk and Joachim Winter, Don't Raise the Retirement Age! An Experiment on Opposition to Pension Reforms and East-West Differences in Germany, August 2009

2753 Daniel G. Arce, Dan Kovenock and Brian Roberson, Suicide Terrorism and the Weakest Link, August 2009

2754 Mario Larch and Wolfgang Lechthaler, Comparative Advantage and Skill-Specific Unemployment, August 2009

2755 Horst Raff and Nicolas Schmitt, Buyer Power in International Markets, August 2009

2756 Seppo Kari, Hanna Karikallio and Jukka Pirttilä, The Impact of Dividend Taxation on Dividends and Investment: New Evidence Based on a Natural Experiment, August 2009

2757 Mirco Tonin and Michael Vlassopoulos, Disentangling the Sources of Pro-social Behavior in the Workplace: A Field Experiment, August 2009

2758 Nicole Grunewald and Inmaculada Martínez-Zarzoso, Driving Factors of Carbon Dioxide Emissions and the Impact from Kyoto Protocol, August 2009

2759 Yu-Fu Chen and Michael Funke, Booms, Recessions and Financial Turmoil: A Fresh Look at Investment Decisions under Cyclical Uncertainty, August 2009

2760 Jan-Egbert Sturm and Jakob de Haan, Does Central Bank Communication really Lead to better Forecasts of Policy Decisions? New Evidence Based on a Taylor Rule Model for the ECB, August 2009 
2761 Larry Karp, Sacrifice, Discounting and Climate Policy: Five Questions, August 2009

2762 Marianna Belloc and Samuel Bowles, International Trade, Factor Mobility and the Persistence of Cultural-Institutional Diversity, August 2009

2763 Charles Noussair and Fangfang Tan, Voting on Punishment Systems within a Heterogeneous Group, August 2009

2764 Birgit Bednar-Friedl and Karl Farmer, Internationally Coordinated Emission Permit Policies: An Option for Withdrawers from the Kyoto Protocol?, August 2009

2765 Pierre M. Picard and David E. Wildasin, Labor Market Pooling, Outsourcing and Labor Contracts, August 2009

2766 Stefan Voigt and Lorenz Blume, The Economic Effects of Federalism and Decentralization - A Cross-Country Assessment, August 2009

2767 David S. Jacks, Christopher M. Meissner and Dennis Novy, Trade Booms, Trade Busts, and Trade Costs, August 2009

2768 Mario Jametti and Thomas von Ungern-Sternberg, Hurricane Insurance in Florida, August 2009

2769 Alessandro Balestrino, Kind of Black: The Musicians’ Labour Market in Italy, August 2009

2770 Yosr Abid Fourati and Cathal O’Donoghue, Eliciting Individual Preferences for Pension Reform, August 2009

2771 Christian Breuer and Chang Woon Nam, VAT on Intra-Community Trade and Bilateral Micro Revenue Clearing in the EU, August 2009

2772 Choudhry Tanveer Shehzad, Jakob De Haan and Bert Scholtens, Growth and Earnings Persistence in Banking Firms: A Dynamic Panel Investigation, August 2009

2773 Erdal Yalcin, Uncertain Productivity Growth and the Choice between FDI and Export, August 2009

2774 Klaus Abberger, Wolfgang Nierhaus and Shynar Shaikh, Findings of the Signal Approach for Financial Monitoring in Kazakhstan, September 2009

2775 Sascha O. Becker, Francesco Cinnirella and Ludger Woessmann, The Trade-off between Fertility and Education: Evidence from before the Demographic Transition, September 2009

2776 Thomas Aronsson and Erkki Koskela, Optimal Income Taxation, Outsourcing and Policy Cooperation in a Dynamic Economy, September 2009

2777 Joel Slemrod, Old George Orwell Got it Backward: Some Thoughts on Behavioral Tax Economics, September 2009 
2778 Cagri Seda Kumru and Athanasios C. Thanopoulos, Social Security Reform and Temptation, September 2009

2779 Alessandro Bucciol and Roel M. W. J. Beetsma, Inter- and Intra-generational Consequences of Pension Buffer Policy under Demographic, Financial and Economic Shocks, September 2009

2780 Eduardo Strube and Marcelo Resende, Complementarity of Innovation Policies in the Brazilian Industry: An Econometric Study, September 2009

2781 Henry Tulkens and Vincent van Steenberghe, "Mitigation, Adaptation, Suffering”: In Search of the Right Mix in the Face of Climate Change, September 2009

2782 Maria L. Loureiro, Anna Sanz-de-Galdeano and Daniela Vuri, Smoking Habits: Like Father, Like Son, Like Mother, Like Daughter, September 2009

2783 Momi Dahan, Tehila Kogut and Moshe Shalem, Do Economic Policymakers Practice what they Preach? The Case of Pension Decisions, September 2009

2784 Eytan Sheshinski, Uncertain Longevity and Investment in Education, September 2009

2785 Nannette Lindenberg and Frank Westermann, How Strong is the Case for Dollarization in Costa Rica? A Note on the Business Cycle Comovements with the United States, September 2009

2786 Leif Danziger, Noncompliance and the Effects of the Minimum Wage on Hours and Welfare in Competitive Labor Markets, September 2009

2787 Gerlinde Fellner, Rupert Sausgruber and Christian Traxler, Testing Enforcement Strategies in the Field: Legal Threat, Moral Appeal and Social Information, September 2009

2788 Gabriel J. Felbermayr, Mario Larch and Wolfgang Lechthaler, Unemployment in an Interdependent World, September 2009

2789 Sebastian G. Kessing, Federalism and Accountability with Distorted Election Choices, September 2009

2790 Daniel Gros, Global Welfare Implications of Carbon Border Taxes, September 2009 